Article

\title{
The Influence of the Highly Concentrated Energy Treatments on the Structure and Properties of Medium Carbon Steel
}

\author{
Sergey N. Grigoriev ${ }^{1}{ }^{\complement}$, Alexandr Yu. Ivannikov ${ }^{2, *}$, Maxim V. Prozhega ${ }^{3}$, Igor N. Zakharov ${ }^{4}$, \\ Olga G. Kuznetsova ${ }^{2}$ and Alexandr. M. Levin ${ }^{2}$ \\ 1 Chair of High-Efficiency Machining Technologies, Moscow State Technological University Stankin, \\ Vadkovskiy Per. 3A, 127055 Moscow, Russia; sngrig.stankin@yandex.ru \\ 2 Baikov Institute of Metallurgy and Material Science, Russian Academy of Sciences, 49, Leninsky Ave., \\ 119334 Moscow, Russia; dik-lab25@yandex.ru (O.G.K.); aba-lab25@yandex.ru (A.M.L.) \\ 3 Mechanical Engineering Research Institute, Russian Academy of Sciences, 4, Maly Kharitonyevsky Pereulok, \\ 101990 Moscow, Russia; prmaksim.imash@yandex.ru \\ 4 Chair of Resistance of Materials, Volgograd State Technical University, 28, Lenin Ave., \\ 400005 Volgograd, Russia; INZ.VSTU@yandex.ru \\ * Correspondence: aivannikov@imet.ac.ru; Tel.: +7-9263411756
}

Received: 30 October 2020; Accepted: 11 December 2020; Published: 14 December 2020

check for updates

\begin{abstract}
This paper describes the effects of combination of electromechanical and ultrasonic treatment on the wear and corrosion behavior of carbon steel AISI 1045. It is shown that the wear resistance of carbon steel AISI 1045 can be improved considerably by hardening the surface. Furthermore, the experimental work indicates that the corrosion rate of the surface decreased because of the combination of the treatments.
\end{abstract}

Keywords: surface; treatment; microhardness; wear; white etched layer

\section{Introduction}

Enhancing the operational properties of products and components, which work in extreme conditions, is one of the most important problems to be solved by mechanical engineering. The quality of this group of products is largely determined by the quality of their surface. The existing traditional technological processes for surface finishing [1-5] do not satisfy the ever-changing requirements of the modern industry. For this reason, the field of the high energy methods for surface finishing offers a large pool of researches and developments [6-12].

Frequently, laser treatment [6,7], electron beam [8-10], and plasma arc [11-13] are used for surface hardening of steels, alloys, and coatings. The industry offers the wide choice of equipment for laser, electron, and plasma treatments, but this equipment is rather expensive. Another type of the high energy methods for surface finishing is ultrasonic treatment. The ultrasonic treatment is used for improving roughness of the surface and, to a lesser extent, for hardening the surface. In practice, ultrasonic equipment can be mounted on lathes, milling machines, and robotic systems for finishing treatment.

Combining thermo-straining methods may be a new way to improve stability of steel and alloy surfaces. Few scientific works describe various combinations of the highly concentrated energy treatments. Lesyk et al. [14] studied combined process of laser surface hardening and ultrasonic impact treatment. The combined treatment improved microgeometry of the surface of the AISI D2 tool steel, hardened the surface almost three times, and formed compressive residual stresses in the near-surface layers. Lv et al. [15] studied the effect of shot peening on fatigue resistance of laser-treated 
20CrMnTi steel. It was shown that the combination of the treatments gave more effect on improving the fatigue and the wear resistance of the steel than the single treatment. A review of literature in the field of the combination of thermo-straining treatments showed that a limited number of studies had reported result. Thus, development of novel techniques is a topical task to improve wear resistance and corrosion resistance of surfaces.

As mentioned above, the expensive equipment is required for hardening the surfaces by means of the laser methods. There are alternative technologies, for example, electric contact surface hardening or electromechanical treatment. Qi et al. [16] studied electric contact surface hardening of ductile iron. It was shown that fatigue limit of ductile iron increased from $693 \mathrm{~N} / \mathrm{mm}^{2}$ to $1054 \mathrm{~N} / \mathrm{mm}^{2}$ after the treatment. Also, this process increased the surface hardness and formed residual compressive stress in the modified zone. In addition, the electric contact surface hardening was used for hardening the coatings [17-19]. Wang et al. [17] used the electric contact surface hardening to improve the adhesion strength of WC-Co coating with substrate from carbon steel. Wang et al. [15] used the electric contact surface hardening to improve the adhesion strength of stainless steel coating with substrate from carbon steel.

On the other hand, in the articles $[20,21]$ the electromechanical treatment (EMT) was used for hardening of the coatings. This approach was based on the combination of pressure by means of the roller with Joule heating of the coating surface. Recently, Ivannikov et al. [22] showed that the EMT improved the wear resistance of the high speed steel coating and decreased the wear rate of the counterfaces.

It is noteworthy to mention that the temperature of the heating zone is measured differently during the laser hardening, the electric contact surface hardening, and the electromechanical treatment. During the laser hardening the direct temperature measurement of the heating zone can be studied by means of an optical pyrometer [23]. During the electric contact surface hardening and the electromechanical treatment the heat zone is closed by the treatment roller, so the direct temperature of the contact zone cannot be measured. For this reason, Qi et al. [24] used theoretical and experimental analysis of the electric contact surface hardening of ductile iron. The temperature field of the surface was simulated using ANSYS software. It was shown that the temperature of the contact zone was above $1400{ }^{\circ} \mathrm{C}$. The simulated results were proven by experimental data. The numerical modelling of the EMT process was made in the study of Ivannikov et al. [25]. The cooling rate in the contact zone was calculated depending on the current density, it was more than $10^{4} \mathrm{~K} / \mathrm{s}$. The formation of the nanostructured crystal phases verified the numerically simulated high cooling rate during the EMT process.

Bearing in mind that the surface of the steel can be treated by means of the electromechanical treatment with high cooling rate, we can assume this method for the surface treatment of the AISI 1045 steel. In practice, the EMT can be realized on the same machine as the ultrasonic treatment (UT). Thus, these methods can be combined for the surface treatment of the steels and alloys.

Recently, Lesyk et al. [26] studied the combined process of the laser surface hardening and the ultrasonic impact treatment. The highest corrosion resistance enhancement was observed after the combined treatment.

The purpose of this work is to estimate the influence of the combination of the treatments $(\mathrm{EMT}+\mathrm{UT})$ on the structure and on the wear and corrosion behavior of AISI 1045 medium carbon steel.

\section{Materials and Methods}

\subsection{Material Selection}

An as-received AISI 1045 mild carbon steel (with nominal composition in wt.\%: 0.5\% Mn, 0.45\% C, $0.17 \% \mathrm{Si}, 0.04 \% \mathrm{~S}, 0.035 \% \mathrm{P}$, balance $\mathrm{Fe}$ ) was machined to cylinders with a diameter of $32 \mathrm{~mm}$ and a length of $30 \mathrm{~mm}$ (Figure 1a). About 12 cylinders were taken as the specimens for testing. These specimens were numbered \#1-12 and were divided into three groups with four samples per 
group. The specimens \#1-4 were not treated, the specimens \#5-8 were treated using the EMT, and the specimens \#9-12 were treated using first the EMT and then the ultrasonic treatment.

The steel ShKh15 (chemical composition in wt.\%: 1.00-1.05 C, 1.60-1.65 Cr, $\leq 0.37$ Si, $\leq 0.4$ Mn, Fe constituted the balance) with a hardness of $50 \mathrm{HRC}$ was used for samples (counterfaces). The counterfaces for wear testing were cylinders (Figure 1b).
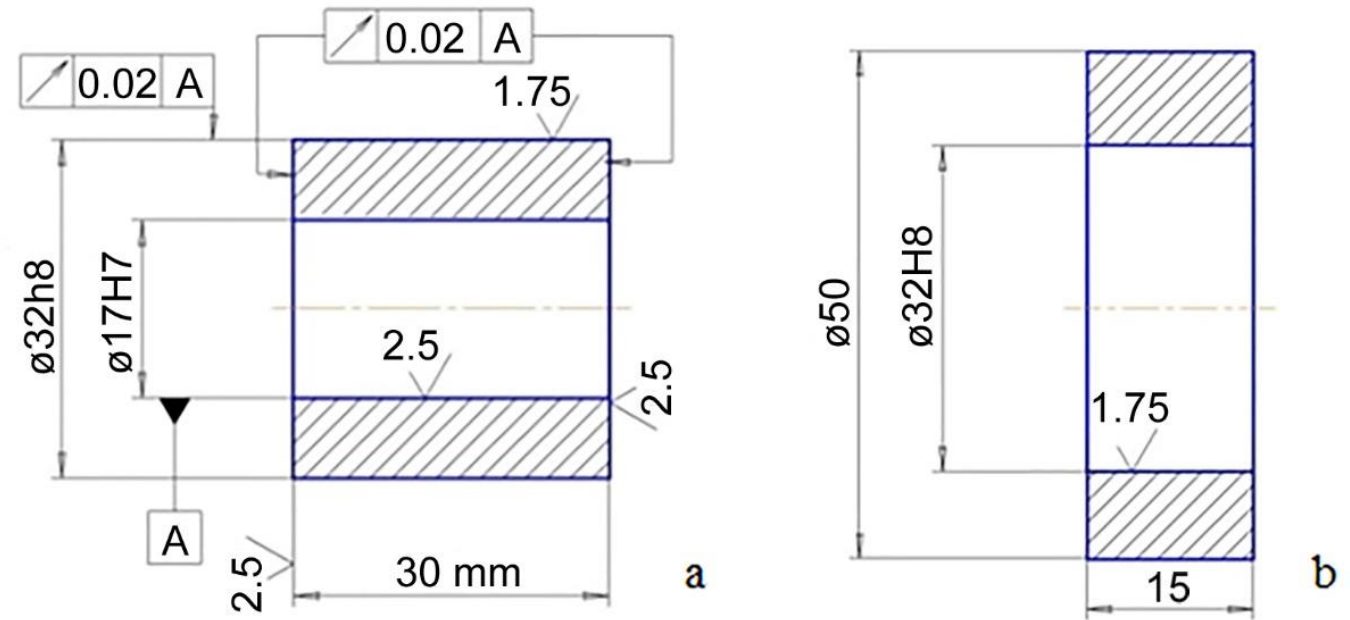

Figure 1. The scheme of the specimens for the wear test: (a) shaft, (b) bearing.

\subsection{The Electromechanical Treatment}

The EMT was chosen for surface hardening. The surface hardening of the cylindrical specimens was performed on a screw-cutting lathe. The EMT was performed using the protocol, which was described earlier [22]. In this work, a scheme with a single contact roller (Figure 2a) was used for the surface hardening. A contact welding transformer was used for the power supply. The control of the current in the secondary circuit was carried out by means of a thyristor power regulator. A contact electrode was used for resistive surface heating. The contact electrode had the shape of a roller and was made from WC-6Co. The roller was $38 \mathrm{~mm}$ in diameter and had the width of the contact surface of $0.5 \mathrm{~mm}$. The contact area between the roller and the specimen surface was determined by the diameter of the roller and the specimen, as well as the width of the contact surface of the roller. A dynamometric device was used to press the roller on the surface of the specimen. The pressure of the roller on the specimen surface was set by the compression force of the spring. The contact area between the roller and the specimen surface was approximately $1 \mathrm{~mm}^{2}$. The compression force of the spring was $150 \mathrm{~N}$. The linear velocity of the heating zone was determined by the rotation speed of the lathe spindle and the diameter of the specimen. The longitudinal displacement of the contact heating zone was set by the feed of the tool holder. Water cooling was used to protect the specimen surface and the roller from overheating. The water jet was supplied to the point of contact between the surface of the specimen and the roller. Therefore, the surface was simultaneously cooled to accelerate the hardening process, as well as the roller was cooled to increase its resource. The specimens \#5-12 were treated by the EMT.

In our other articles we have already evaluated the effect of current density, linear speed, feed rate, and contact force with different parameters. Therefore, the optimal of them were determined earlier [27]. The main modes of the EMT are summarized in the Table 1. 


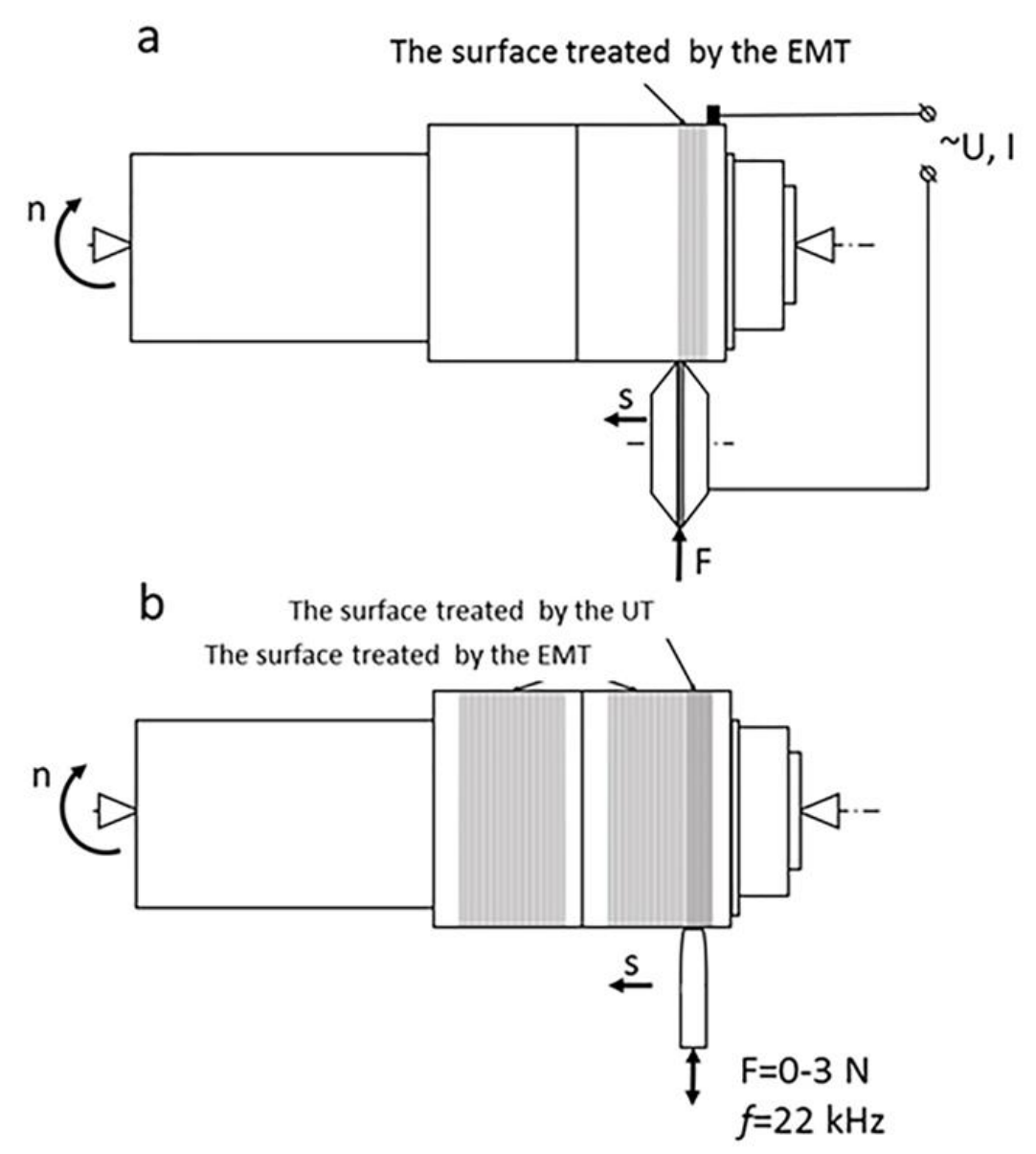

Figure 2. The principal schematic diagram of the surface treatment: (a) the electromechanical treatment, (b) the ultrasonic treatment.

Table 1. Modes of the treatments.

\begin{tabular}{ccccc}
\hline Treatment & $\begin{array}{c}\text { Feed Rate } \boldsymbol{s}, \\
\mathbf{m m} / \mathbf{r e v}\end{array}$ & $\begin{array}{c}\text { Linear Velocity } \boldsymbol{V}, \\
\mathbf{m} / \mathbf{m i n}\end{array}$ & $\begin{array}{c}\text { Density of the Electric } \\
\text { Current } \mathbf{j}, \mathbf{A} / \mathbf{m m}^{2}\end{array}$ & Contact Force $\boldsymbol{P}, \mathbf{N}$ \\
\hline EMT & 0.4 & 2.5 & 400 & 250 \\
\hline UT & 0.1 & 6 & - & 3 \\
\hline
\end{tabular}

\subsection{The Ultrasonic Treatment}

The ultrasonic treatment (UT) of the specimen surface was done after the EMT. The UT of the cylindrical specimens was performed on the same screw-cutting lathe (Figure 2b, SAMAT, Samara, Russia). The equipment contained an ultrasonic generator with a power output of $0.3 \mathrm{~kW}$ and a frequency of $21.6 \mathrm{kHz}$ (BUFO, Saint Petersburg, Russia). The high frequency impacts were produced by a cylindrical WC-6Co pin of $5 \mathrm{~mm}$ in diameter.

The specimens \#9-12 were treated by the UT. The linear velocity of the treated zone was determined by the rotation speed of the lathe spindle and the diameter of the specimen. The longitudinal displacement was set by the feed of the tool holder. Water cooling was used to protect the specimen surface and the cylindrical pin from overheating. The main modes of the UT are summarized in the Table 1. 


\subsection{Analysis of Surface}

The specimens \#1, 5, 9 were taken to determine the properties of the surface. The specimen \#1 had no additional treatment. The specimen \#5 was treated by the EMT. The specimen \#9 was treated by the EMT and then treated by the UT.

To develop the samples with cross-section, the specimens \#1, 5, 9 were cut, mounted in plastic and polished. $1 \mu \mathrm{m}$ diamond suspension was used for the last polishing stage.

After polishing, the samples were washed with ethyl alcohol and dried. Then the cross-sections of the specimens were etched in the bath $4: 1 \mathrm{H}_{2} \mathrm{O}-\mathrm{HNO}_{3}$ for metallography.

An optical microscope (Carl Zeiss Jenavert Interphako, Carl Zeiss, Oberkochen, Germany) was used to study the structure and the morphology of the surface. The investigation of the surface layer microstructure was carried out on a scanning electron microscope (Carl Zeiss NVision 40, Carl Zeiss, Oberkochen, Germany) with high resolution. Measurements of roughness, depth of the WEL, and length of the lath were made with the image analyzer, having software of VideoTest Structure 4.0 (VideoTest OOO, St. Petersburg, Russia).

\subsection{The Microhardness Test}

The microhardness of the surface layer was analyzed. The Vickers indenter (PMT-3) was used to measure the microhardness of the surface layer. For each sample the microhardness was conducted 15 times and the obtained values were averaged. These measurements were taken by applying a load of $200 \mathrm{gf}(1.96 \mathrm{~N})$ and dwell time of $15 \mathrm{~s}$ (according to ISO 6507-1:2005).

The microhardness of the area of the thin surface layer was determined in the cross-section of the specimens under the load of $0.098 \mathrm{~N}$ ( $10 \mathrm{gf}$ ) for $15 \mathrm{~s}$. The indentation of $10 \mathrm{gf}$ was applied to the surface area (Figure 3) to measure the microhardness allocation in the surface after the treatment. The indentations were made by array in the cross-section of the surface layer. The distance between the indents was more than 4 diagonals of the indentation.

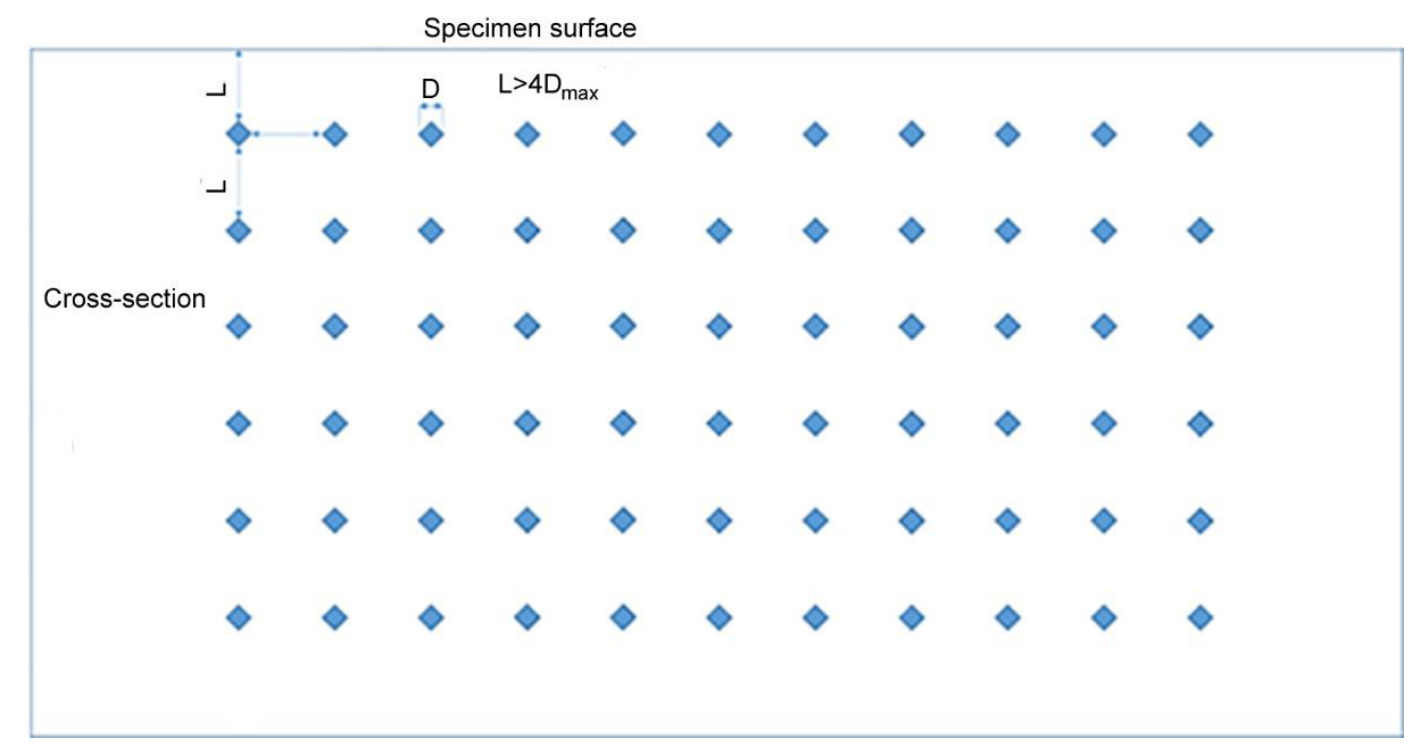

Figure 3. The schematic diagram of indentation at the load of $10 \mathrm{gf}$ in the cross-section of the specimen.

\subsection{The Wear Resistance Test}

The wear resistance test was carried out on the test machine SMT-1 (LLC "Tochpribor", Ivanovo, Russia).

The test principle was the following: the bush was radially loaded against the shaft (Figure 4). In all the experiments, the linear velocity was kept constant at $1.68 \mathrm{~m} / \mathrm{s}$ and the constant specific pressure was $0.24 \mathrm{MPa}$. The sliding distance was $18,000 \mathrm{~m}$. Before and after the testing, both the test 
sample and the counterface were degreased and cleaned with acetone, then they were dried in warm air to ensure accuracy of measurements. The test samples were weighed on the analytical balance (AJH, Shinko Denshi, Tokyo, Japan) with accuracy of $0.1 \mathrm{mg}$ before, during, and after each test to calculate the mass loss. The mass loss was converted to the volume loss using measured values of the samples densities. The wear rate was calculated.

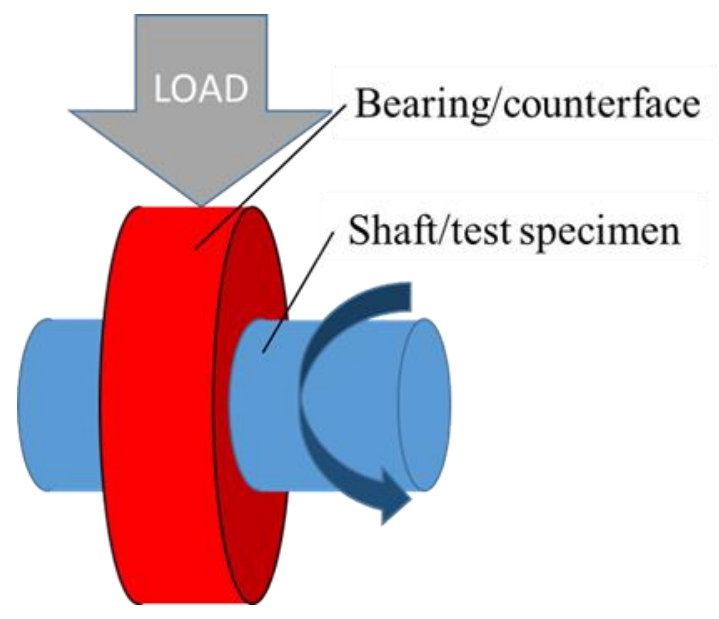

Figure 4. Test principle: bearing is radially loaded against shaft.

\subsection{The Corrosion Test}

The corrosion tests were performed using a computerized potentiostat/galvanostat P-45X (Electrochemical Instruments, Chernogolovka, Russia).

The corrosion circuit consisted of three electrodes: a platinum sheet as a counter electrode, AISI 1045 as a working electrode, and a saturated calomel electrode (SCE) as a reference electrode. $0.9 \%$ $\mathrm{NaCl}$ solution was used as the electrolyte. The potentiostatic/galvanostatic study was performed from -0.5 to $+0.5 \mathrm{~V}$ at a fixed scan rate of $1.0 \mathrm{mV} / \mathrm{s}$.

\subsection{Numerical Modeling}

The experimental investigation of the temperature in the contact zone between the roller and the treated surface cannot be performed by the optical pyrometer because the heating zone was closed by the treatment roller. For this reason, the temperature field in the surface layer, the rate of heating and cooling during the process of the EMT were numerically calculated. The mathematical approach to modeling of the temperature field was considered in detail in the paper [28]. The solution of the thermal conductivity equation (Fourier's equation) was calculated using the finite difference method.

Figure 5 shows a half-space with a heat source, it simulates surface heating during resistive heating by the electrode. During the treatment the rise and fall of the electric current follow a sinusoidal function. The frequency of the electric current was $50 \mathrm{~Hz}$. Consequently, after the start of the impulse the amplitude of the electric current had a maximum value every $5 \mathrm{~ms}$. Then the amplitude of the electric current decreased to zero. An electric current of $400 \mathrm{~A}$ was used for the calculation, as in the experiment. The shape of the contact zone between the roller and the treated surface of the specimen was close to the elliptical. The dimensions of the heat source in the mathematical model were 1.7 and $0.6 \mathrm{~mm}$, respectively. The contact area was approximately $1 \mathrm{~mm}^{2}$. The linear velocity of the heat source on the surface was assumed to be $2.5 \mathrm{~m} / \mathrm{min}$, which corresponded to the linear velocity of the resistive heating zone during experiment. 


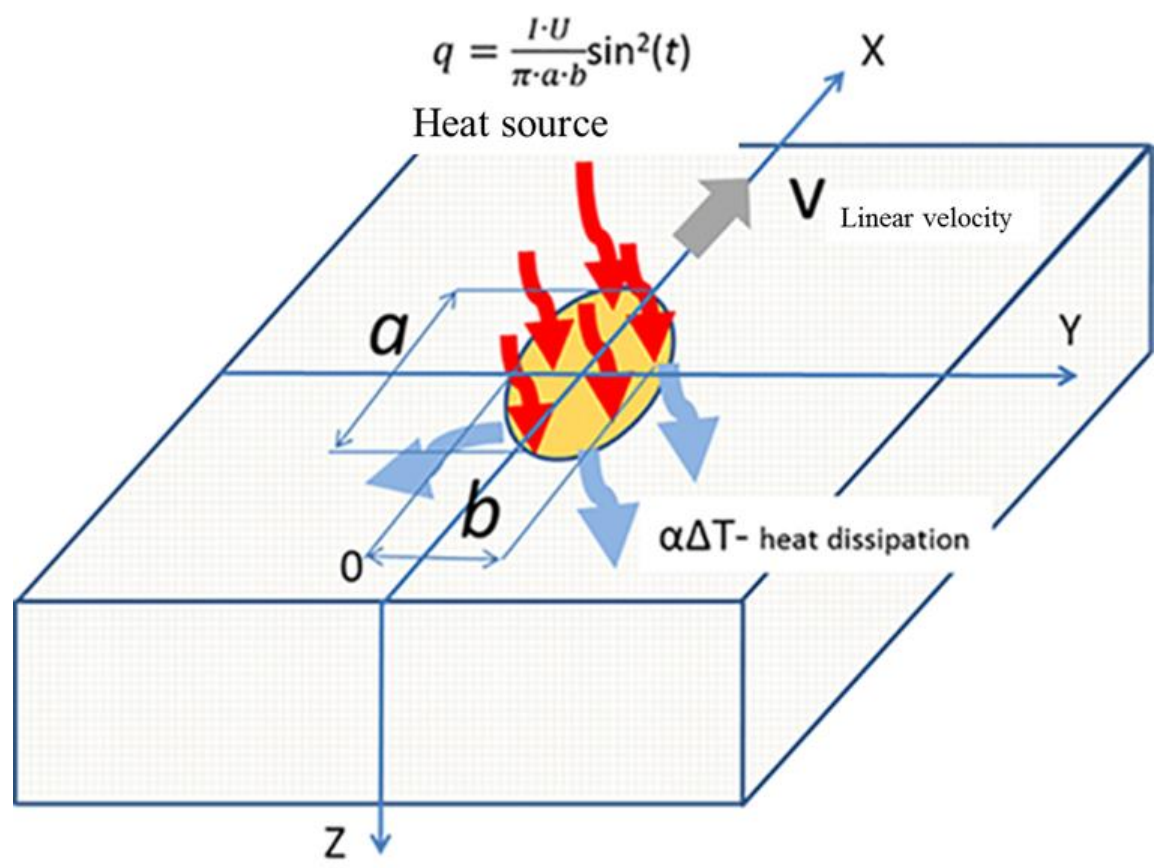

Figure 5. The model of a half-space with a moving thermal source on the surface.

\section{Results and Discussion}

\subsection{Macrostructure and Microstructure}

Figure 6 shows optical microscopy of the cross-sections of the base metal, the electromechanically treated steel, and the electromechanically and ultrasonically treated steel. Figure 6a shows ferrite-pearlite structure of the AISI 1045 steel. Figure 6b,c recovers the white etched layer (WEL) in the surface of the cross-section after the EMT. The average depth of the WEL is $240 \pm 20 \mu \mathrm{m}$. The heat affected zones are observed between the WELs. The heat affected zones are formed while the roller moves longitudinally and some part of the previously fabricated WEL is heated the second time. The ferrite-pearlite structure is detected in the HAZ.

Figure $6 \mathrm{~b}$ shows wavy structure. The period of the wavy structure is approximately $400 \mu \mathrm{m}$, due to the constant longitudinal movement of the roller $(0.4 \mathrm{~mm} / \mathrm{rev})$. During the EMT with the single roller, the surface under the roller was resistively heated. The plasticity of the material increased. Under the influence of the contact pressure, the material of the surface layer was squeezed out from under the roller. The wavy structure of the surface was formed. A similar effect was found in the paper [25], where the wavy structure was formed during the EMT of the plasma sprayed coating. There is no wavy structure after finishing the surface by means of UT (Figure 6c). During the UT the wavy structure is deformed and the microrelief of the surface is improved. The average depth of the WEL after the additional UT was $210 \pm 10 \mu \mathrm{m}$. During the UT the surface layer was heated, for this reason, the average depth of the WEL decreased.

In the previous study [27] the optical microscopy could not examine the structure of the WEL. In addition, the modelling of the electromechanical treatment [28] showed that the heating temperature of the surface layer was more than $1000 \mathrm{~K}$. As a result, the $\gamma$-iron dissolved carbon and did so by consuming the cementite. Consequently, the austenite was formed in the surface layer. The cooling rate during the EMT process indicated that it exceeded $104 \mathrm{~K} / \mathrm{s}$, there was not enough time for the reverse transformation and the carbon could not diffuse out of its lattice. The austenite was distorted into tetragonal shape. The martensite was formed with the strained lattice. It was assumed that the martensite had grain size less than $0.5 \mu \mathrm{m}$ and could not be examined by means of the optical microscopy. 


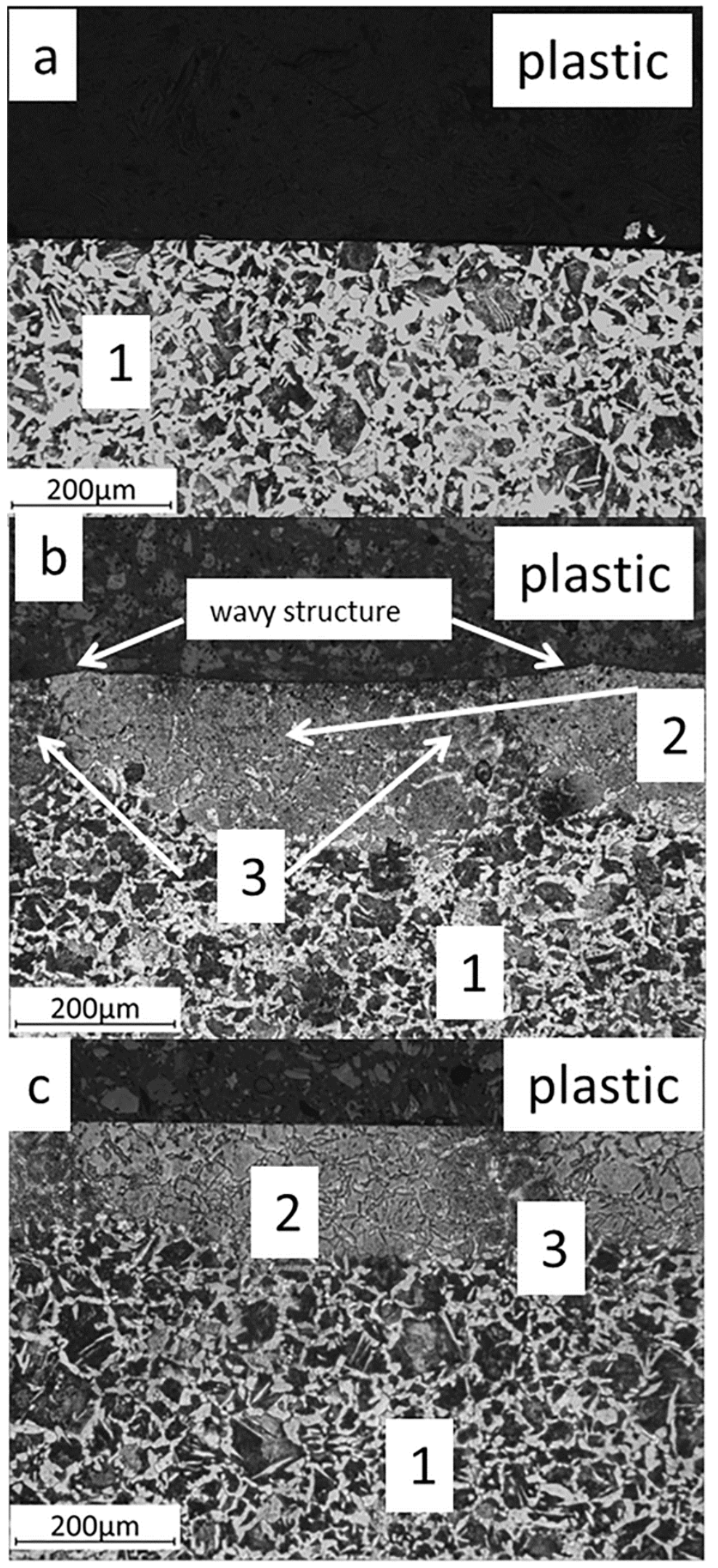

Figure 6. Optical microscopy of the cross-section: (a) AISI 1045, (b) after the electromechanical treatment (EMT), (c) after the combination of the treatments (EMT + UT). 1-the ferrite-pearlite structure, 2-the WEL, 3-the HAZ. 
In this study, we used high-resolution scanning electron microscopy for examination of the structure of the WEL. Figure 7 shows the microstructure of the WEL. The lath martensite is formed after the EMT of the surface of the AISI 1045. The length of the lath is $0.50 \pm 0.25 \mu \mathrm{m}$ and the average thickness is $100 \pm 25 \mathrm{~nm}$. The length and the thickness of the structure in the WEL are less than $0.5 \mu \mathrm{m}$ each. For this reason, the optical microscopy could not be used for examination of the structure of the WEL. The comparison of the structure of the WEL after the EMT and after the laser treatment [26] showed that these types of the highly concentrated energy treatments gave the similar structure of the lath martensite in the surface layer of the AISI 1045 steel.

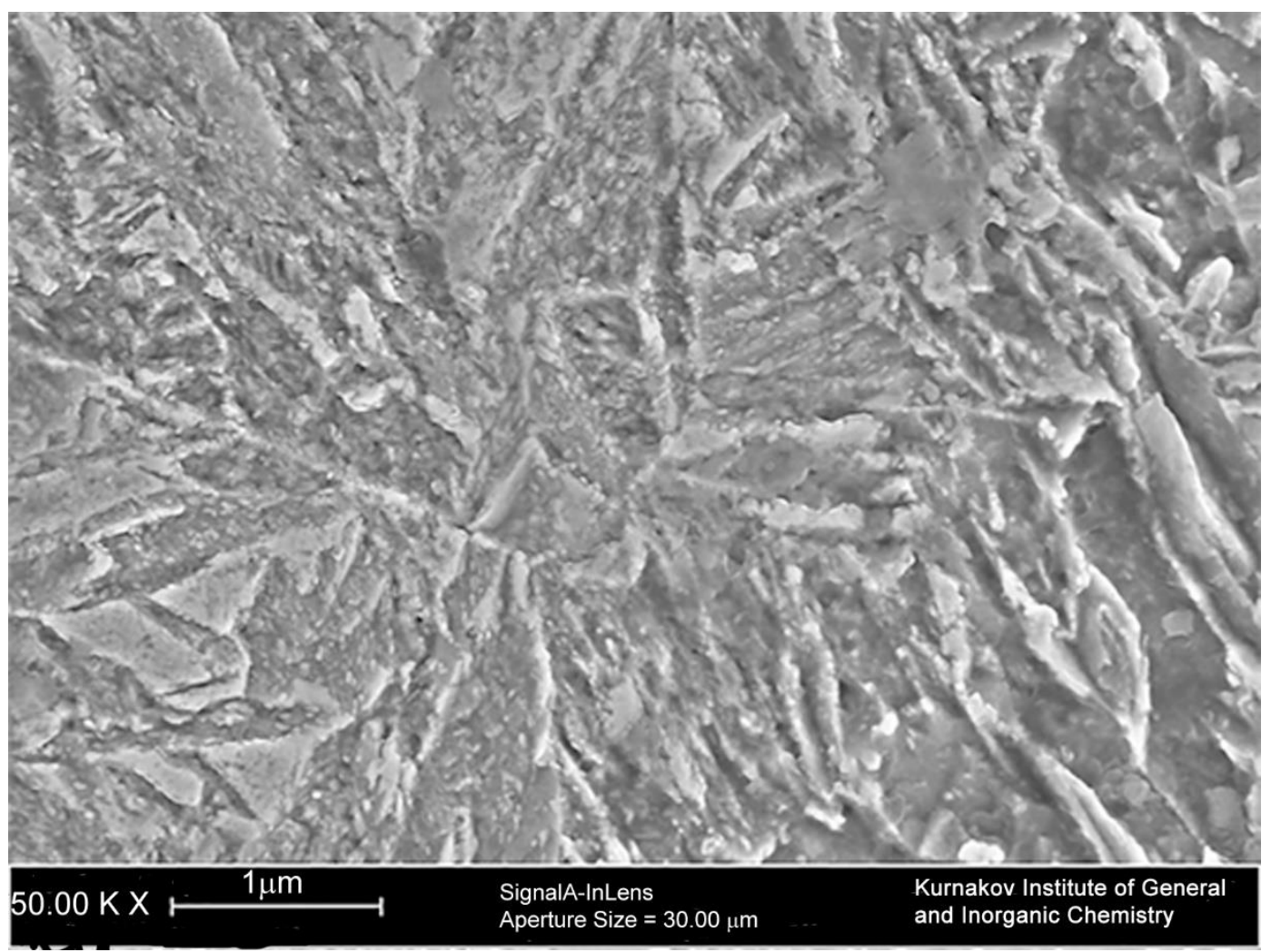

Figure 7. SEM of the white etched layer.

\subsection{Microhardness}

Table 2 shows the average microhardness of the surface layer and the average microhardness of the structural elements.

The microhardness of the WEL is 1.9 times more than the microhardness of the heat-affected zone. The average microhardness of the surface layer increases by $10 \%$ after the ultrasonic treatment. The microhardness at the load of $10 \mathrm{gf}$ of the heat-affected zone of the surface layer increases, too.

Figure 8 shows the distributions of the microhardness at the load of $10 \mathrm{gf}$ in the cross-section of the surface after the EMT. Three zones are observed in Figure 8. The first zone is the WEL, the microhardness of this area is more than $5000 \mathrm{MPa}$. The second zone is the heat affected zone, its microhardness changes from 3000 to $5000 \mathrm{MPa}$. The third zone has microhardness less than $3000 \mathrm{MPa}$, this is the base AISI 1045 steel. 


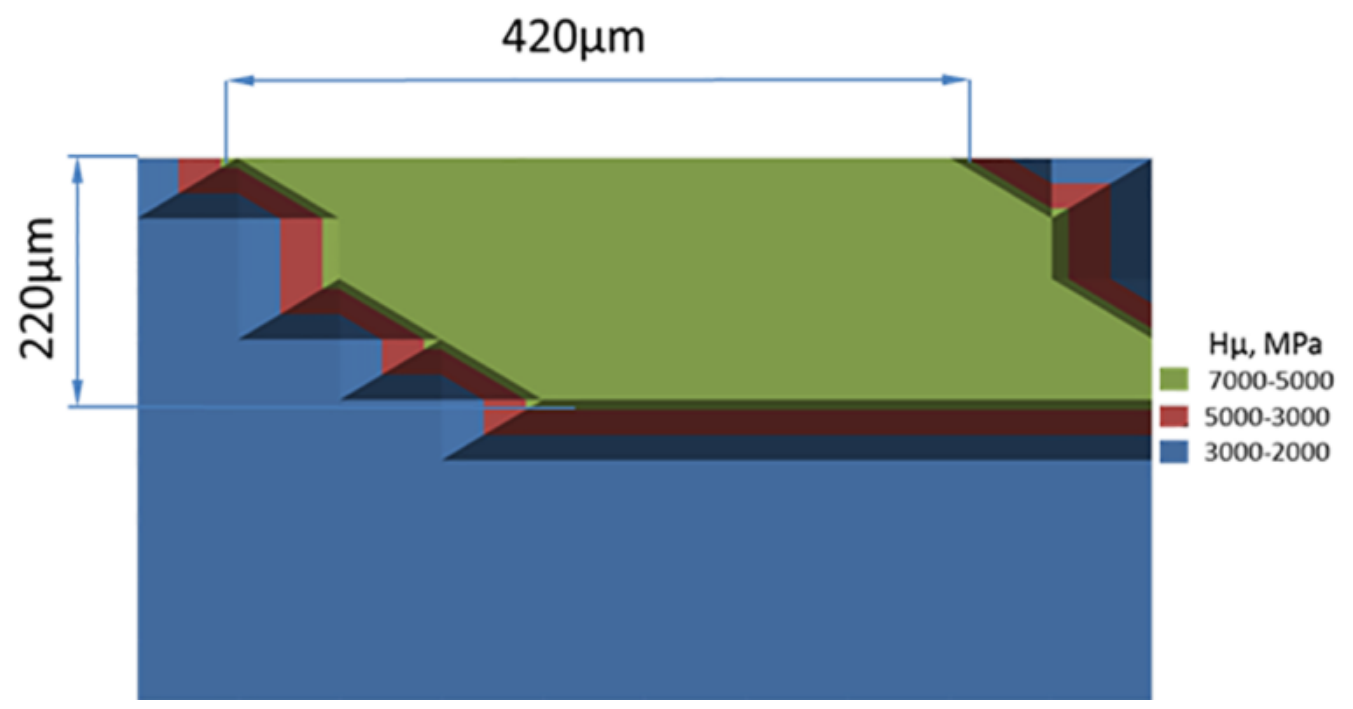

Figure 8. Distributions of the microhardness at the load of $10 \mathrm{gf}$ in the cross-section of the surface after the EMT.

Table 2. Microhardness of the cross-section of the surface layer.

\begin{tabular}{cccc}
\hline \multirow{2}{*}{ Type of Treatment } & \multicolumn{3}{c}{ Microhardness, MPa } \\
\cline { 2 - 4 } & $\mathbf{2 0 0}$ gf & \multicolumn{2}{c}{$\mathbf{1 0}$ gf } \\
\cline { 2 - 4 } & & WEL & Heat Affected Zone \\
\hline As-received AISI 1045 & $2000 \pm 100$ & $2000 \pm 150$ & - \\
\hline EMT & $5000 \pm 400$ & $6800 \pm 500$ & $3500 \pm 500$ \\
\hline EMT + UT & $5500 \pm 400$ & $7000 \pm 500$ & $4500 \pm 500$ \\
\hline
\end{tabular}

\subsection{Numerical Modeling}

Figure 9 shows the temperature field in the cross-section of the half-space at a time of $25 \mathrm{~ms}$ after the start of the EMT. At this moment the maximum temperature was observed on the surface. The value of the heating temperature was $1700 \mathrm{~K}$, which was higher than the melting temperature. But there was no melting of the surface layer because of the cooling of the base metal. The calculation of the cooling rate during the EMT process indicated that it exceeded $10^{4} \mathrm{~K} / \mathrm{s}$. The calculated data were confirmed by structural studies (Figure $6 \mathrm{~b}$ ), which reiterated that there was no melting of the surface layer. The thickness of the heating zone (Figure 9) with a temperature higher than $1000 \mathrm{~K}$ and the thickness of the WEL (Figure $6 \mathrm{~b}$ ) were approximately equal. In addition, the analysis of the temperature distribution (Figure 9) and the distribution of the microhardness (Figure 8) showed that by moving to the region where the heating temperature was less than $1000 \mathrm{~K}$ the value of the microhardness reduced a lot. 


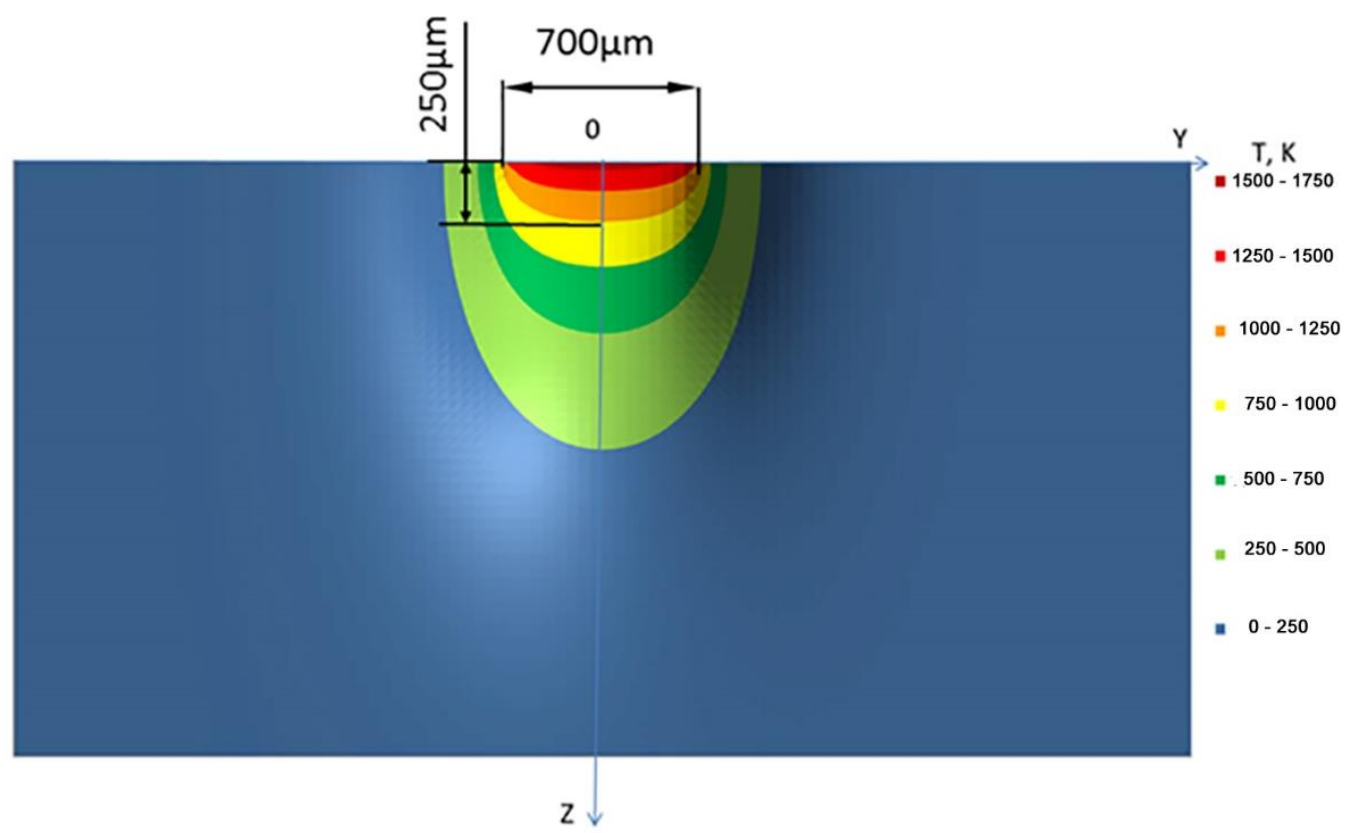

Figure 9. The calculated distribution of the temperature in the cross-section of the surface layer at 25 ms during the EMT.

\subsection{Wear Behavior}

The effect of the combination of the treatments on the wear behavior of the AISI 1045-improved steel was investigated by the sliding wear tests.

Figure 10 shows the wear rate of the specimens. The wear rate of the AISI 1045 steel decreased from $0.357 \pm 0.050 \mathrm{~mm}^{3} / \mathrm{min}$ to $0.160 \pm 0.011 \mathrm{~mm}^{3} / \mathrm{min}$, because the microhardness at the load of $200 \mathrm{gf}$ of AISI 1045 steel increased from $2000 \pm 100 \mathrm{MPa}$ to $5000 \pm 400 \mathrm{MPa}$ after the EMT. After the combination of the treatments the microhardness at the load of $200 \mathrm{gf}$ increased to $5500 \pm 400 \mathrm{MPa}$, but the wear rate remained stable.

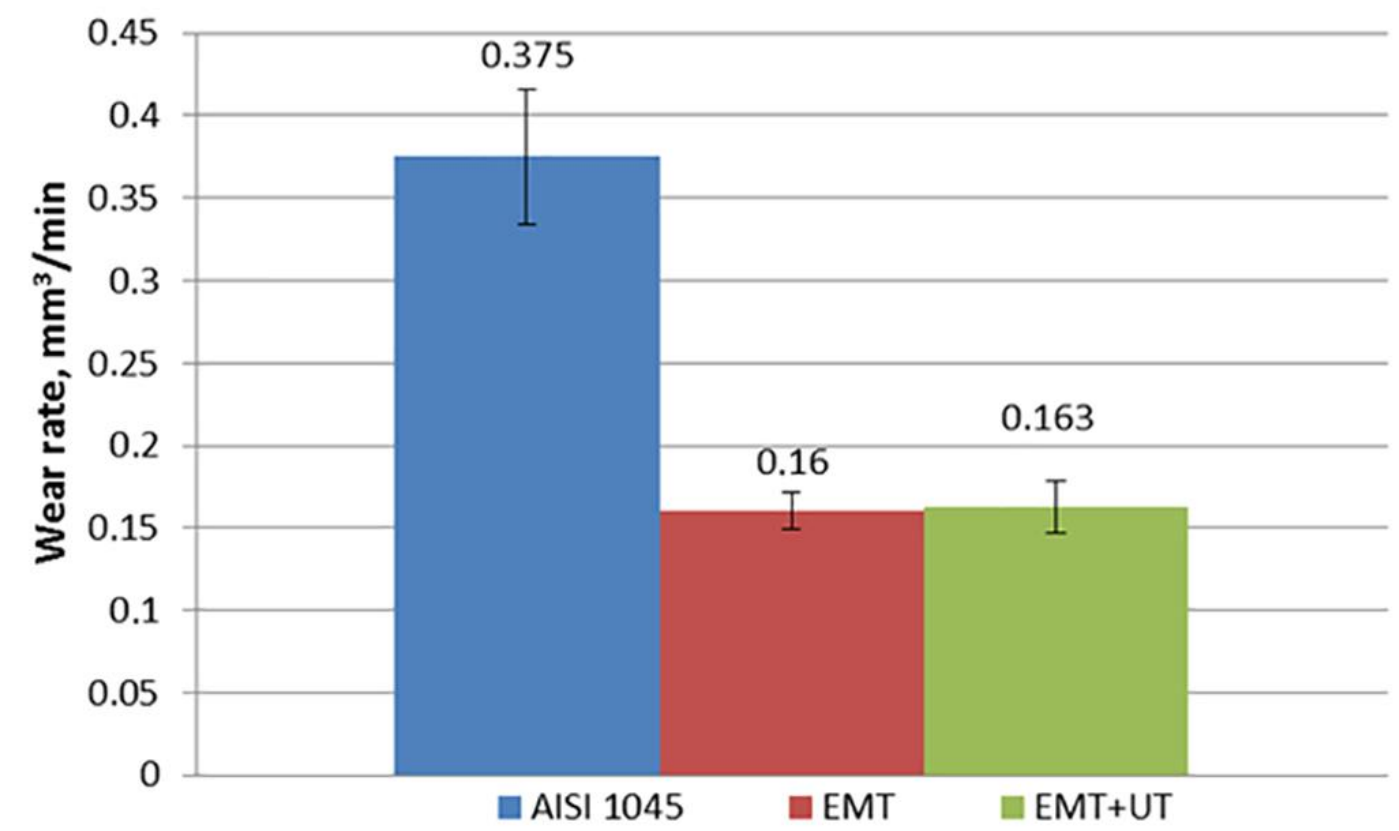

Figure 10. The wear rate of the specimens. 
Figure 11 shows the SEM image of the surface morphology of the produced wear scar by the sliding wear test. The sliding distance was $18,000 \mathrm{~m}$, and the normal load was set as $113.4 \mathrm{~N}$. In the case of the base metal, thick abrasion grooves, spalling, and delamination are observed at the wear scar, confirming that the dominant wear mechanism is a mix of adhesive and abrasive mechanisms. Spalling and delamination may cause unstable wear behavior, resulting in large fluctuation in the wear rate, as shown in Figure 10. Contrastingly, in the case of the EMT, relatively less spalling is detected; however, thick abrasion grooves are still observed at the wear scar. In the case of the combination of treatments the wear behavior was the same as after the EMT.

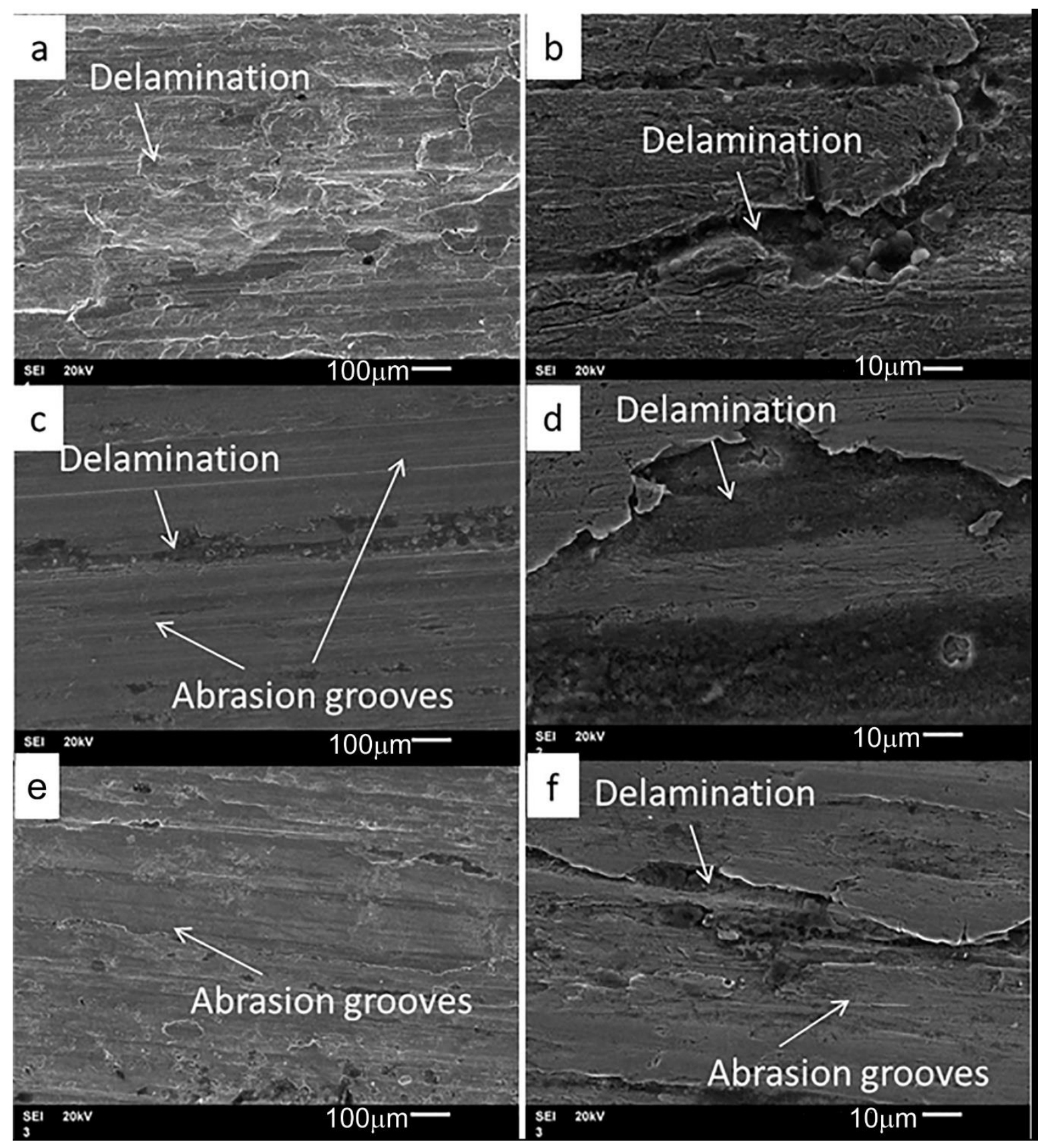

Figure 11. The worn surface morphologies from the sliding wear tests after $18,000 \mathrm{~m}$ of sliding distance at a normal load of $113.4 \mathrm{~N}$ (a,b-AISI 1045, c,d-after the EMT, e,f-after the EMT + UT). 


\subsection{Corrosion Behavior}

Figure 12 displays the polarization curves for the base metal (1), after the EMT (2), and after combination of the EMT + UT (3).

For the base metal, the corrosion potential is found to be $-0.503 \mathrm{~V} / \mathrm{SCE}$. The marginal shift in the corrosion potential to the noble direction $(-0.484 \mathrm{~V} / \mathrm{SCE})$ is observed on the surface of the sample after the EMT. In the case of the combination of the EMT + UT, the corrosion potential is shifted to $-0.496 \mathrm{~V} / \mathrm{SCE}$.

After the EMT and the combination of the treatments the growth of the polarization curves is slower. The interval from $100 \mathrm{mV}$ to $350 \mathrm{mV}$ shows the effect of the passivation for polarization curves on the surface of the sample after the combination of the treatments.

When the corrosion potential is $500 \mathrm{~V} / \mathrm{SCE}$, the anodic current density tends to be diverse. The anodic current density of the AISI 1045 steel is $2828 \mu \mathrm{A} / \mathrm{cm}^{2}$. After the EMT the anodic current density decreases to $1025 \mu \mathrm{A} / \mathrm{cm}^{2}$. The minimal anodic current density is $728 \mu \mathrm{A} / \mathrm{cm}^{2}$ and this value is observed after the combination of the treatments.

This study estimated the influence of the combination of the treatments on the wear and corrosion behavior of AISI 1045-improved steel. However, the mechanical properties such as yield strength and fatigue strength also have an impact on the lifetime of the steel. The correlation between the microstructure and the mechanical properties after the combination of the treatments will be investigated in future researches.

The EMT allows to perform the hardening process on a lathe. Therefore, the hardening is carried out on the same equipment. There is no need to use additional rooms or equipment. In addition, the EMT allows strengthening of local areas, for example, cutter slots or fillets of shafts. It is also possible to strengthen large-sized items or items with complex geometry.

The microstructure of the white layer, formed during the hardening of the EMT and the laser hardening, is the same. Therefore, the EMT can replace the laser hardening, because the cost of the equipment is several times lower.

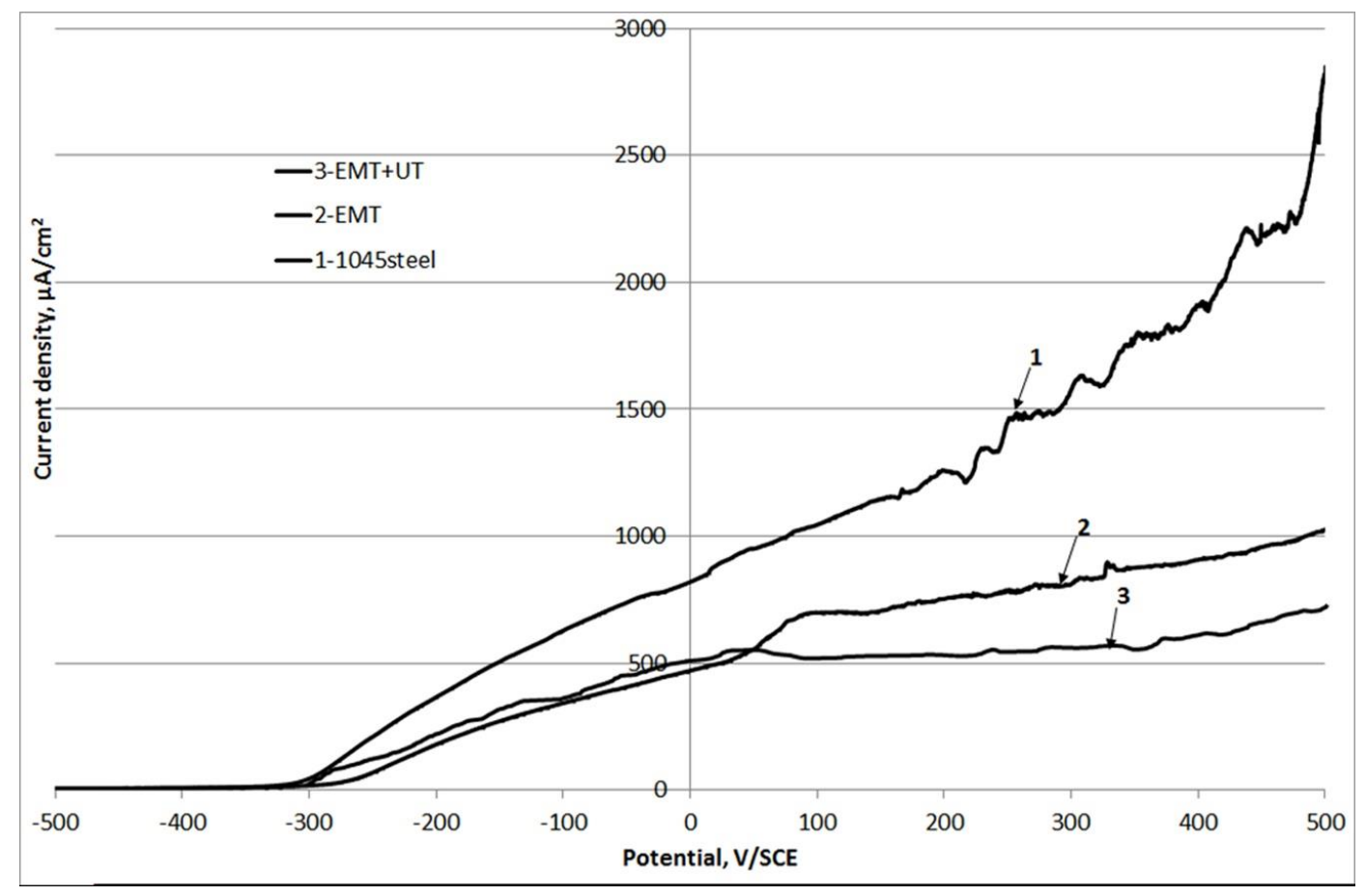

Figure 12. The polarization curves of the base AISI 1045 (1), the EMT treated surface AISI 1045 (2), and the EMT + UT treated surface AISI 1045 (3) in $0.9 \% \mathrm{NaCl}$ solution. 


\section{Conclusions}

During the EMT process the WEL was formed in the surface layer. The microhardness of the surface layer of steel AISI 1045 increased from $2000 \pm 100 \mathrm{MPa}$ to $5000 \pm 400 \mathrm{MPa}$ after the EMT. The high microhardness of the WEL was caused by the transformation of the structure of AISI 1045 steel from ferrite-perlite to lath martensitic with the average thickness less than $100 \mathrm{~nm}$.

The formation of a fast-quenched structure of the WEL in the surface layer confirmed the calculated data of the cooling rate during the EMT process of more than $10^{4} \mathrm{~K} / \mathrm{s}$.

The formation of the wavy structure during the EMT process was determined by the extrusion of the surface material from under the roller during the combined action of resistive heating and contact pressure. Therefore, the period of the wavy structure coincided with the step of the roller movement when scanning the surface of the cylindrical specimen.

The UT cleaned the wavy structure and increased the microhardness of the surface after the EMT up to $5500 \pm 500 \mathrm{MPa}$. The wear resistance of treated using the EMT and the UT steel increased more than two times compared to the base steel.

The anodic current density of the surface of the AISI 1045 steel decreased two times after the EMT because of the formation of the white-etched layer. The anodic current density of the surface of the AISI 1045 steel was decreased three times after the combination of the treatments because of the hardening of the heat-affected zones which were formed during the EMT process.

Author Contributions: S.N.G.: supervision, validation, funding acquisition. A.Y.I.: surface treatment, investigation of the structure, conceptualization, writing-review and editing. M.V.P.: investigation of the tribology properties. I.N.Z.: software. O.G.K. and A.M.L.: preparation of the specimens, investigation of the corrosion properties. All authors have read and agreed to the published version of the manuscript.

Funding: This work was supported by the Russian Science Foundation (project No. 18-19-00599).

Acknowledgments: The authors are grateful to Yulia Ivannikova for the technical support.

Conflicts of Interest: The authors declare that they have no known competing financial interests or personal relationships that could have appeared to influence the work reported in this paper.

\section{References}

1. Shiou, F.-J.; Cheng, C. Ultra-precision surface finish of NAK80 mould tool steel using sequential ball burnishing and ball polishing processes. J. Mater. Process. Technol. 2008, 201, 554-559. [CrossRef]

2. Bell, T. Surface engineering of austenitic stainless steel. Surf. Eng. 2002, 18, 415-422. [CrossRef]

3. Savaria, V.; Monajati, H.; Bridier, F.; Bocher, P. Measurement and correction of residual stress gradients in aeronautical gears after various induction surface hardening treatments. J. Mater. Process. Technol. 2015, 220, 113-123. [CrossRef]

4. Rudnev, V.; Loveless, D.; Cook, R.; Black, M. Handbook of Induction Heating; Marcel Dekker: New York, NY, USA, 2003.

5. Santhanakrishnan, S.; Dahotre, N.B. Laser surface hardening. In ASM Handbook on Heat Treating Irons and Steels; American Society for Materials (ASM) International: Materials, Park, OH, USA, 2013.

6. Grum, J. Comparison of different techniques of laser surface hardening. J. Achiev. Mater. Manuf. Eng. 2007, $24,17-25$.

7. Montross, C.S.; Wei, T.; Ye, L.; Clark, G.; Mai, Y.-W. Laser shock processing and its effects on microstructure and properties of metal alloys: A review. Int. J. Fatigue 2002, 24, 1021-1036. [CrossRef]

8. Zou, J.; Zhang, K.; Hao, S.; Dong, C.; Grosdidier, T. Mechanisms of hardening, wear and corrosion improvement of 316L stainless steel by low energy high current pulsed electron beam surface treatment. Thin Solid Films 2010, 519, 1404-1415. [CrossRef]

9. College, D.A.; Zhu, Y. Alleviating surface tensile stress in e-beam treated tool steels by cryogenic treatment. Mater. Sci. Eng. A 2018, 722, 167-172. [CrossRef]

10. Zhang, K.; Ma, J.; Zou, J.; Liu, Y. Surface microstructure and property modifications in a duplex stainless steel induced by high current pulsed electron beam treatments. J. Alloy Compd. 2017, 707, 178-183. [CrossRef] 
11. Ismail, M.I.S.; Taha, Z. Surface Hardening of Tool Steel by Plasma Arc with Multiple Passes. Int. J. Technol. 2014, 5, 79-87. [CrossRef]

12. Wang, L.M.; Liu, J.B.; Huang, B.X. Microstructure and Performance of Multiple Tracks Lap-Joint Coating by Plasma Cladding. Appl. Mech. Mater. 2011, 109, 42-45. [CrossRef]

13. Som, A.I. Iron-based alloy for plasma-powder surfacing of screw conveyors of extruders and injection molding machines. Pat. Weld. J. 2016, 7, 21-25. [CrossRef]

14. Lesyk, D.; Martinez, S.; Mordyuk, B.; Dzhemelinskyi, V.; Lamikiz, A.; Prokopenko, G.; Milman, Y.; Grinkevych, K. Microstructure related enhancement in wear resistance of tool steel AISI D2 by applying laser heat treatment followed by ultrasonic impact treatment. Surf. Coat. Technol. 2017, 328, 344-354. [CrossRef]

15. Lv, Y.; Lei, L.; Sun, L. Influence of different combined severe shot peening and laser surface melting treatments on the fatigue performance of 20CrMnTi steel gear. Mater. Sci. Eng. A 2016, 658, 77-85. [CrossRef]

16. Qi, X.B.; Zhu, S. Effect of electric contact surface treatment on microstructure and wear behaviour of ductile iron. Mater. Sci. Technol. 2013, 29, 1310-1316. [CrossRef]

17. Wang, Y.; Zhu, S.; Gu, W.; Qi, X. Electric Contact Strengthening to Improve the Bonding between Thermally Sprayed 316 Stainless Steel Coating and 45\# Steel Substrate. Exp. Tech. 2010, 35, 66-70.

18. YWang, Y.; Zhu, S.; Gu, W.; Qi, X. Electric Contact Strengthening to Improve the Bonding Between WC-Co Coating and 45\# Steel Substrate. J. Therm. Spray Technol. 2010, 19, 1142-1146.

19. Xu, M.; Zhu, S.; Ding, H. Electrical contact strengthening of induction-clad Ni-40\% WC composite coatings on 40Cr substrates. Surf. Coat. Technol. 2015, 279, 32-38. [CrossRef]

20. Bagmutov, V.P.; Kalita, V.I.; Zakharova, E.B.; Komlev, D.I.; Ivannikov, A.Y.; Zakharov, I.N.; Kosogorov, A.V. Ultradisperse and nano structures in plasma coatings hardened by electromechanical treatment. Steel Transl. 2013, 43, 351-355. [CrossRef]

21. Ivannikov, A.Y.; Kalita, V.; Komlev, D.; Radyuk, A.; Bagmutov, V.; Zakharov, I.N.; Parshev, S. The effect of electromechanical treatment on structure and properties of plasma sprayed Ni-20Cr coating. J. Alloy Compd. 2016, 655, 11-20. [CrossRef]

22. Ivannikov, A.Y.; Kalita, V.I.; Komlev, D.I.; Radyuk, A.; Bagmutov, V.; Zakharov, I.N.; Parshev, S. The effect of electromechanical treatment on structure and properties of plasma sprayed Fe-6W-5Mo-4Cr-2V-C coating. Surf. Coat. Technol. 2018, 335, 327-333. [CrossRef]

23. Cordovilla, F.; García-Beltrán, Á.; Sancho, P.; Domínguez, J.; Ruiz-De-Lara, L.; Ocaña, J.L. Numerical/experimental analysis of the laser surface hardening with overlapped tracks to design the configuration of the process for Cr-Mo steels. Mater. Des. 2016, 102, 225-237. [CrossRef]

24. Ben Qi, X.; Zhu, S.G. Study on Electric Contact Heating for Nodular Cast Iron 600-3. Appl. Mech. Mater. 2012, 154, 316-321.

25. Ivannikov, A.Y.; Kalita, V.I.; Komlev, D.I.; Radyuk, A.A.; Alpatov, A.V.; Zakharov, I.N.; Grigoriev, S.N.; Prozhega, M.V. The Effect of Electromechanical Treatment on Structure and Properties of Plasma-Sprayed Fe-30Cr Coating. J. Therm. Spray Technol. 2019, 28, 883-892. [CrossRef]

26. Lesyk, D.; Mordyuk, B.; Martinez, S.; Iefimov, M.; Dzhemelinskyi, V.; Lamikiz, A. Influence of combined laser heat treatment and ultrasonic impact treatment on microstructure and corrosion behavior of AISI 1045 steel. Surf. Coat. Technol. 2020, 401, 126275. [CrossRef]

27. Dudkina, N.G.; Zakharov, I.N.; Ermolov, V.S.; Ivannikov, A.Y. Dependence of microhardness of a regular discrete structures of the surface layer of a mild steel on the conditions of electromechanical treatment. Probl. Mashinostr. Nadezhn. Mashin 2006, 5, 62-68. (In Russian)

28. Bagmutov, V.P.; Denisevich, D.S.; Zakharov, I.N.; Ivannikov, A.Y. Nonlinear and coupled thermal effects during finite element simulation of contact thermoforce surface hardening. PNRPU Mech. Bull. 2017, $1,233-250$.

Publisher's Note: MDPI stays neutral with regard to jurisdictional claims in published maps and institutional affiliations. 